\title{
Caudal Ropivacaine with Clonidine as Adjuvant In Infra- Umbilical Pediatric Surgeries for Intra-Operative And Post- Operative Analgesia: An Observational Clinical Study
}

\author{
Vinod Kumar Verma ${ }^{1}$, Chandrakant Prasad $^{2}$, Arvind Kumar ${ }^{3}$, Gunjan Kumar ${ }^{4}$, \\ Rajesh Kumar \\ ${ }^{1}$ (Additional Professor, Department Of Anaesthesiology\&Critical Care Medicine, I.G.I.M.S, Patna, \\ Bihar, India) \\ ${ }^{2}$ (Junior Resident, Department Of Anaesthesiology \&Critical Care Medicine, I.G.I.M.S, Patna, Bihar, India) \\ ${ }_{3}^{3}$ (Assistant Professor, Department Of Anaesthesiology\&Critical Care Medicine, I.G.I.M.S, Patna, Bihar, India) \\ 4,5 (Senior Resident,DepartmentOf Anaesthesiology\&Critical Care Medicine, I.G.I.M.S, Patna, Bihar, India)
}

\begin{abstract}
Background: The aim of the study was to assess the efficacy of ropivacaine with clonidine as an adjuvant given via single shot caudal epidural in pediatric patients for intraoperative and postoperative pain relief.

Materials and Methods: In this study, 30 children of ASA-I-II, aged 1-6 years scheduled for infra-umbilical surgical procedures were given ropivacaine $0.125 \% 1 \mathrm{ml} / \mathrm{kg}+$ clonidine $1 \mu \mathrm{g} / \mathrm{kg}$ as single shot caudal epidural analgesia. Caudal block was performed after the induction of generalanesthesia. Postoperatively patients were observed for analgesia, sedation, hemodynamics, and side effects/complications.

Results: All the patients exhibited stable hemodynamics. There was good intraoperative and postoperative analgesia. No patient required intraoperative rescue analgesic. Side effects such as respiratory depression, vomiting, bradycardia, hypotension, residual motor blockade, pruritus were statistically insignificant.

Conclusions:Ropivacaine with clonidine has prolonged duration of analgesia after single shot caudal epidural administration. This combination offers some advantages as it does not produce clinically and statistically significant undesirable side effects like respiratory depression, vomiting and bradycardia. So we can use clonidine as adjuvant to ropivacaine in caudal analgesia, in children, as it has a more favorable side effect profile.

Keywords:Caudal epidural, clonidine, pediatric, postoperative analgesia, ropivacaine
\end{abstract}

\section{Introduction}

Caudal epidural block is one of the most popular and commonly performed regional blocks in pediatricanaesthesia. It is a safe and reliable technique that can be used with general anaesthesia for intraoperative and postoperative analgesia in patients undergoing surgical procedures below the umbilicus ${ }^{1}$. Various long acting local anaesthetics have been used for pediatric caudal block with various advantages, disadvantages and adverse effects. Levobupivacaine and Ropivacaine are the long acting amide local anaesthetics used for pediatric caudal block with various concentrations ranging from $0.125 \%$ to $0.5 \%$ and $0.1 \%$ to $0.75 \%$ respectively. Profound motor block and systemic toxicity are the problems encountered with higher concentrations and volumes of local anaesthetics, which can be minimized by reducing the concentration and dosage of the drugs. The main disadvantage of this single shot caudal block is its shorter duration of action even with the use of long acting local anaesthetic agents such as Levobupivacaine and Ropivacaine ${ }^{2}$. This leads to early appreciation of pain by the child postoperatively.

Therefore it is the duty of the anaesthesiologist to provide good postoperative analgesia. To avoid epidural catheter placement and yet prolong the duration and improve the quality of intra-operative and postoperative analgesia of local anaesthetics, various drugs like Opioids ${ }^{3,4,5}$ Midazolam $^{6}$, ketamine ${ }^{7}$, Neostigmine ${ }^{8}$, Clonidine ${ }^{8,9}$ etc have been used as adjuvants with various results. Clonidine, an alpha 2 adrenergic agonist is known to produce analgesia of variable intensity and duration, which is dose dependent ${ }^{10}$. It has been used as an adjuvant with different dosages ranging from $1 \mu \mathrm{g} / \mathrm{kg}$ to $3 \mu \mathrm{g} / \mathrm{kg}$ in pediatric caudal block. Clonidine is used as an adjuvant with local anesthetics like Lignocaine, Bupivacaine, Levobupivacaine and Ropivacaine in caudal block to improve the intra-operative and postoperative analgesia and to reduce the dose of local anesthetics, thereby reducing the toxicity of local anesthetics.

For infra-umbilical surgeries where post-operative analgesia is the main concern and motor blockade is not required, lower concentrations and volumes of local anaesthetics with lower doses of Clonidine can be used, so that the side effects of these drugs can be reduced further. 
In this study we assessed the safety, efficacy and duration of analgesia of low volumes and concentrations of local anesthetics (Ropivacaine $0.125 \%$ at a volume of $1 \mathrm{ml} / \mathrm{kg}$ ) with a low dose of Clonidine $(1 \mu \mathrm{g} / \mathrm{kg}$ ) as an adjuvant for caudal block in children undergoing infra-umbilical surgeries.

\section{Material And Methods}

After obtaining approval from institutional ethical committeeand written informed consent from parents, 30 ASA I-II patients aged 1-6 years, weighing $5-20 \mathrm{~kg}$, scheduledto undergo infra-umbilical surgical procedures such as hernia repair, orchidopexy, hypospadias, and urethroplastywere enrolled in the study [Power of the study was $80 \%$ (alphaerror $=05 \%$ ). Children withlocal infection of the caudal area, history of allergic reactions to local anesthetics, bleeding diathesis, preexisting neurologicalor spinal diseases, mental retardation, neuromuscular disorders were excluded from the study.

Basal vital parameters like heart rate, blood pressure and Oxygen saturation of patient were recorded after connecting with monitor. Inj. Atropine $0.01 \mathrm{mg} / \mathrm{kg}$ iv and Inj. Midazolam $0.03 \mathrm{mg} / \mathrm{kg}$ iv were given as premedication 1 hour before induction. Patients were induced with inj. Propofol $2 \mathrm{mg} / \mathrm{kg}$ iv, inj. Fentanyl 1.5 $\mathrm{mcg} / \mathrm{kg}$ i.v.\&injatracurium $0.5 \mathrm{mg} / \mathrm{kg}$ iv and then endotracheal intubation was done. After confirmation of bilateral air entry ET tube was fixed at the angle of mouth to secure its position. Anaesthesia was maintained with Oxygen, nitrous oxide, halothane by using the Jackson Rees circuit. Intermittent atracurium was given as per requirement. The child was put in the left lateral position and under aseptic precautions the sacral hiatus was identified. Caudal epidural space was identified by using the loss of resistance technique and the studied drug (Ropivacaine $0.125 \% 1 \mathrm{ml} / \mathrm{kg}$ with clonidine $1 \mu \mathrm{g} / \mathrm{kg}$ ) was deposited after confirming negative aspiration for blood and CSF. Time of administration of drug was noted. After the completion of surgery neuromuscular block was reversed with the usual reversal agent (neostigmine $0.05 \mathrm{mg} / \mathrm{kg}+$ glycopyrrolate $0.01 \mathrm{mg} / \mathrm{kg}$ ).

Heart rate (HR), mean arterial pressure (MAP) and oxygen saturation $\left(\mathrm{SpO}_{2}\right)$ were recorded before induction of anaesthesia ( Baseline), after induction but before caudal anaesthesia, every 5 minsintraoperatively and every 15 mins postoperatively. An increase or decrease in the HR $>15 \%$ from the baseline values was considered as tachycardia or bradycardia. Similarly, an increase or decrease in MAP $>15 \%$ was considered as hypertension or hypotension. Absence of rise of HR or MAP of more than 15\% compared with baseline values recorded just before surgical incision wasconsidered as adequate analgesia. An increase in HR or MAP $(>15 \%)$, 15 min after administration of caudal anesthesia was defined as failure of analgesia. If HR, MAPincreased 45 min after surgical incision it was considered as inadequate analgesia. Patients with failure of caudal analgesia or inadequate analgesia were given fentanyl $1 \mathrm{mcg} / \mathrm{kg}$ intravenously. Patients, in whom caudal anesthesia failed or inadequate analgesia was present, were excluded from study. Time from caudal block to skin incision, duration of surgery and duration of general anesthesia were recorded. In PACU analgesia, sedation, HR, MAP, SPO2, and side effects were monitored every $15 \mathrm{mins}$ for 6 hours, and thereafter $1 / 2$ hourly till $12 \mathrm{hrs}$ after caudal block.

Pain was assessed using observational Pain Scale [Table 1]. If patients had score of $>3$ on at least 2 occasions or showed obvious signs of pain they were given Paracetamolsuppository $15 \mathrm{mg} / \mathrm{kg}$ as rescue analgesic. The duration of postoperative analgesia was defined as time interval between caudal anesthesia and first complaint of pain. Assessment of sedation was done every 15 mins after surgery using 4 point sedationscore [Table 2]. SpO2 was monitored continuously and $\mathrm{SpO} 2<95 \%$ was defined as desaturation. Assessment of duration of motor blockade was done by noting the time from caudal block to regain modified bromage score 0 (Table 3). Time of micturition was defined as time from administration of caudal block to spontaneous voiding of urine. Side effects like nausea, vomiting, respiratory depression, pruritus hypotension, and bradycardia were also noted. Statistical analysis was doneusing student t-test and chi-square test. $P$ value $<0.05$ was regarded as statistically significant. 


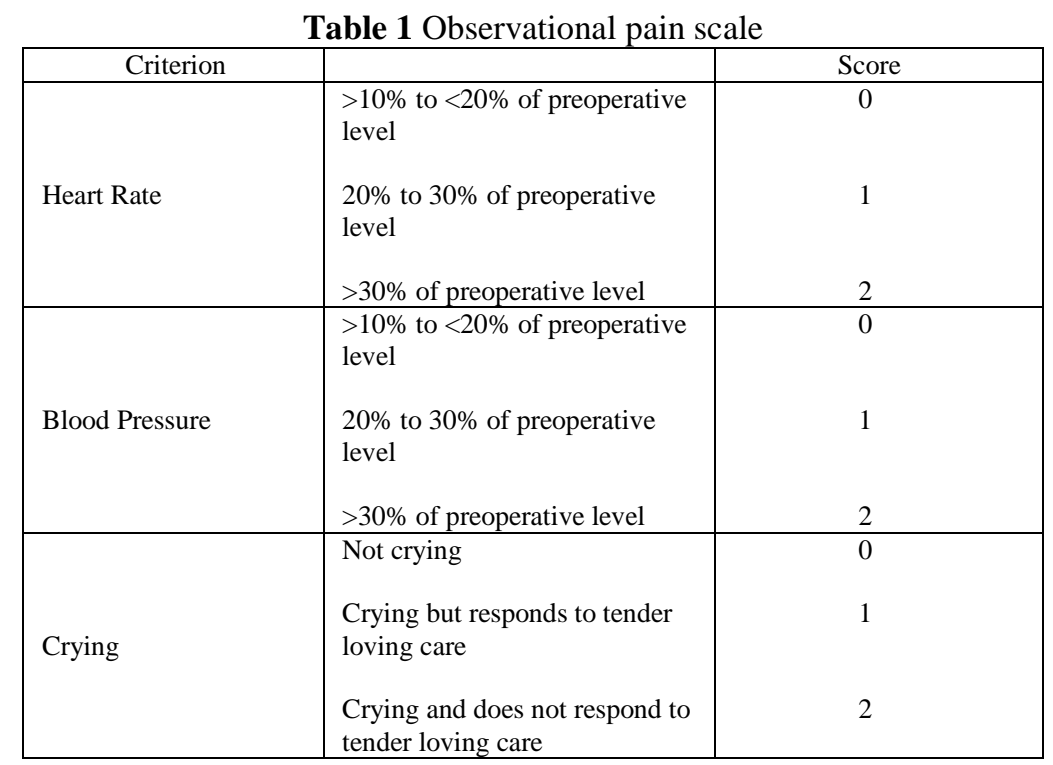

Table2Sedation score

\begin{tabular}{|c|l|}
\hline Sedation score & \multicolumn{1}{c|}{ Criterion } \\
\hline 1 & asleep, not arousable by verbal contact \\
\hline 2 & asleep, arousable by verbal contact \\
\hline 3 & drowsy not sleeping \\
\hline 4 & alert/awake \\
\hline
\end{tabular}

Table 3Modified Bromage score

\begin{tabular}{|l|l|}
\hline Criterion & Score \\
\hline No motor block, child moves limbs freely & 0 \\
\hline Inability to raise legs & 1 \\
\hline Inability to flex knees & 2 \\
\hline No movement possible in legs & 3 \\
\hline
\end{tabular}

\section{Results}

Thirty pediatric patients were studied. Demographic and clinical data is given in table 4 . The baseline mean heart rate was $132.72 \pm 11.86 / \mathrm{min}$ and at the end of the procedure was $115.25 \pm 6.36 / \mathrm{min}$. The baseline mean arterial pressure was $69.13 \pm 3.16 \mathrm{mmHg}$ and at the end of theprocedure was $64.33 \pm 3.54 \mathrm{mmHg}$.Intraoperatively there was a minimal fall in the heart rate and no significant variation in the meanarterial pressure(table 5). Mean duration of surgery was $54.22 \pm 5.42$ mins. Surgical analgesia was found to be adequate. No patient required intraoperative rescue analgesia. Postoperatively there were no significant changes in the vital parameters until the child experienced pain when there was an increase in heart rate. The mean duration of sedation was $138.66 \pm 13.21$ mins. There was no motor blockade in any of the patient. The duration of analgesia was $423 \pm 23.21$ mins. Rescue doses of Paracetamol suppository $15 \mathrm{mg} / \mathrm{kg}$ was given when the child complained of pain or when the pain/ discomfort score $>/=3$. Two patients suffered from vomiting and bradycardia occurred in 1 patient. No patient had urinary retention or pruritus (table 6).

Table4Demographic and Clinical data (mean \pm SD)

\begin{tabular}{|l|l|}
\hline \multicolumn{1}{|c|}{ Variable } & Data \\
\hline Age (months) & $39 \pm 4.2$ \\
\hline Weight (kgs) & $12 \pm 3.9$ \\
\hline Sex ratio (M:F) & $23: 07$ \\
\hline Type of surgery & \\
Hernia repair & 16 \\
Hypospadias & 09 \\
Orchidopexy & 02 \\
urethroplasty & 03 \\
\hline Duration of surgery (mins) & $54.22 \pm 5.42$ \\
\hline Duration of Anaesthesia (mins) & $72 \pm 6.45$ \\
\hline
\end{tabular}


Table 5Recording of vitals (mean \pm SD)

\begin{tabular}{|l|l|}
\hline \multicolumn{1}{|c|}{ Variables } & Data \\
\hline Baseline HR (/min) & $132.72 \pm 11.86$ \\
\hline Intra-op HR & $121 \pm 13.76$ \\
\hline Post-op HR & $115.25 \pm 6.36$ \\
\hline Baseline MAP & $69.13 \pm 3.16$ \\
\hline Intra-op MAP & $66.27 \pm 3.69$ \\
\hline Post-op MAP & $64.33 \pm 3.54$ \\
\hline Baseline Spo & $97 \pm 3.0$ \\
\hline Intra-op $\mathrm{Spo}_{2}$ & $97 \pm 2.31$ \\
\hline Post-op $\mathrm{Spo}_{2}$ & $97 \pm 2.79$ \\
\hline
\end{tabular}

Table 6 Complications/ side effects

\begin{tabular}{|l|c|}
\hline \multicolumn{1}{|c|}{ variable } & Data \\
\hline Nausea/vomiting & 2 \\
\hline Respiratory depression & 0 \\
\hline Spo2 $<95 \%$ & 0 \\
\hline Bradycardia & 1 \\
\hline Hypotension & 0 \\
\hline Dry mouth & 0 \\
\hline Urinary retention & 0 \\
\hline
\end{tabular}

\section{Discussion}

Caudal epidural anesthesia is a simple, frequently usedtechnique, which provides very effective analgesia intra- and postoperatively in pediatric patients undergoing infra-umbilical surgeries. The search for the ideal combination of drugs for caudal anesthesia in pediatric patients is on. Efforts are being made to find relatively safer drugs with minimal side effects.Ropivacaine is a local anesthetic with better safety margin and reduced risk of cardiac toxicity. ${ }^{11}$ Separation of sensory and motor effects is more with ropivacaine than with bupivacaine. ${ }^{12}$ Ropivacaine is more commonly used for caudal blocks in pediatric patients. ${ }^{13}$ This study demonstrates that in a single shot caudal block with clonidine added to ropivacaine prolongs analgesia.

Bosenberg $\mathrm{A}^{14}$ et al. demonstrated that ropivacaine $0.2 \%$ provided satisfactory postoperative pain relief, while $0.1 \%$ was less effective and $0.3 \%$ was associated with higher incidence of motor block with minimal improvement in pain relief. Wedesigned this study keeping this in mind.

Various drugs were tried to prolong the duration of analgesia with minimal side effects because the mean duration of analgesia provided with even longer acting local anesthesia is limited. Fentanyl, a lipophilic opioid is very commonly used as an additive to local anesthetics in children. Although there is no debate about its beneficial effects, side effects like respiratory depression, nausea, and vomiting are common. ${ }^{16,17}$ Clonidine an a2 agonist has also been used as additive to local anesthetics, e.g., bupivacaine, ${ }^{27,18}$ mepivacaine, ${ }^{19}$ lignocaine. ${ }^{20}$ Its addition increases duration and improves quality of analgesia provided by single shot caudal anesthesia. Clonidine when used extradurally provides analgesia by nonopioid spinal effects. Clonidine is devoid of opioid side effects but may produce excessive sedation, hypotension, and bradycardia in adults. $^{21}$

In the present study, addition of clonidine toropivacaine was found to be effective in providing effective intraoperative and postoperative analgesia. Respiratory depression is an expected but unwanted side effect of extradural opioid; ${ }^{22}$ it has also been noticed in adult patients whoreceived clonidine $300 \mathrm{mg}$ extradurally. ${ }^{23}$ Many previous studies have however not reported respiratory depression after caudal administration of clonidine ${ }^{17,18,20,24}$ in pediatric patients. A sedative effect was observed after epidural clonidine in adults ${ }^{23}$ and to a lesser degree in children. ${ }^{17,18}$ Hypotension and bradycardia are expected side effect of extradural clonidine in adults ${ }^{21}$ and depend on the dose administered, however in children the hemodynamic effects of extradural clonidine are less pronounced than in adults. ${ }^{17,18,24}$ No patient had hypotension. one patient suffered from bradycardia, but this was not significant. No patient had a fall in HR to less than 80 beats per minute. So they exhibited stable hemodynamics.

Two patients out of 30 had vomiting in postoperative period. The extradural opioids are well known for their emetic effect while clonidine has anti-emetic properties when administered orally ${ }^{25}$ or intravenously. ${ }^{26}$ so clonidine has lesser side effects when used as adjuvant to local anaesthetics in pediatric caudal block.

\section{Conclusion}

The addition of clonidine toropivacaine prolongs the duration of analgesia after single shot caudal epidural administration. Clonidine offers some advantages as it does not produce clinically and statistically significant undesirable side effects like respiratory depression, vomiting and bradycardia. So wecan 
useclonidine as adjuvant to ropivacaine in caudal analgesia, in children, as it has a more favorable side effect profile.

\section{References}

[1]. J C Sanders, "Paediatric regional anaesthesia, a survey of practice in the United Kingdom" British Journal of Anaesthesia 2002;89:707-710

[2]. T G Hansen et al, S W Henneberg, S Walther Larsen, J Lund, M Hansen, "Caudal

[3]. Bupivacaine supplemented with caudal or intravenous Clonidine in children undergoing hypospadias repair: a double blind study" British Journal of Anaesthesia

[4]. 2004;92:223-227

[5]. PankajKundra, K Deepalakshmi, M Ravishankar, "Preemptive Caudal Bupivacaine and Morphine for Postoperative Analgesia in Children" Anaesthesia

[6]. Analgesia 1998;87:52-56 81

[7]. A HomChoudhuri, P Dharmani, N Kumarl, A Prakash, "Comparison of caudal

[8]. epidural Bupivacaine with Bupivacaine plus Tramadol and Bupivacaine plus Ketamine for postoperative analgesia in children" Anaesthesia and Intensive Care 2008;36(2):174-179

[9]. MeenaDoda, Sambrita Mukherjee, "Postoperative Analgesia in Children- Comparative Study between Caudal Bupivacaine and Bupivacaine plus Tramadol" Indian Journal of Anaesthesia 2009;53(4):463-466

[10]. Mohamed Naguib, Mohamed El Gammal, Yasser S Elhattab, Mohamed Seraj,"Midazolam for caudal analgesia in children: comparison with caudalBupivacaine" Canadian Journal of Anaesthesia 1995;42(9):758-76.

[11]. M Naguib, A M Y Sharif, M Seraj, M El Gammal, A ADawlatly, "Ketamine forCaudal analgesia in children: comparison with caudal Bupivacaine" BritishJournal of Anaesthesia 1991;67:559-564

[12]. Mohamed Abdulatif, Mohga El Sanabary, "Caudal Neostigmine, Bupivacaine andtheir combination for postoperative pain management after Hypospadias surgeryin children” Anaesthesia Analgesia 2002;95:1215-1218

[13]. I Constant, O Gall, L Gouyet, M Chauvin, I Murat, "Addition of Clonidine orFentanyl to local anaesthetics prolongs the duration of surgical analgesia aftersingle shot caudal block in children” British Journal of Anaesthesia 1998;80:294-298

[14]. Joel G Hardman, "Pharmacological basis of therapeutics" Goodman and Gilman,10th edition, 2001, 233-234

[15]. Reiz S, Häggmark S, Johansson G, Nath S. Cardiotoxicityofropivacaine: A new amide local anaesthetic agent. ActaAnaesthesiolScand 1989;33:93-8.

[16]. Markham A, Faulds D. Ropivacaine: A review of its pharmacologyand therapeutic use in regional anaesthesia. Drugs 1996;52:42949.

[17]. Hannallah RS, Broadman LM, Belman AB, Abramowitz MD,Epstein BS: Comparison of Caudal and ilioinguinal/iliohypogastricnerve blocks for control of post-orchiopexy pain in pediatric

[18]. ambulatory surgery. Anesthesiology 1987;66:832-4.

[19]. Eisenach JC, De Kock M, Klimscha W. Alpha(2)- adrenergic agonistfor regional anesthesia: A clinical review of clonidine (19841995).Anesthesiology 1996;85:655-74.

[20]. Bosenberg A, Thomas J, Lopez T, Lybeck A, HuizarK,Larsson LE. The efficacy of caudal ropivacaine 1, 2 and 3 mg xl(-1) for postoperative analgesia in children. PaediatrAnaesth2002;12:53 -8.

[21]. Campbell FA, Yentis SM, Fear DW, Bissonnette B. Analgesic efficacyand safety of a caudal bupivacaine-fentanyl mixture in children.Can J Anaesth 1992;39:661-4.

[22]. Jamali S, Monin S, Begon C, Dubousset AM, Ecoffey C. Clonidinein pediatric caudal anaesthesia. AnesthAnalg 1994;78:663-6.

[23]. Lee JJ, Rubin AP. Comparison of a bupivacaine-clonidine mixturewith plain bupivacaine for caudal analgesia in children. Br JAnaesth 1994;72:258-62.

[24]. Ivani G, Mattioli G, Rega M, Conio A, Jasonni V, de NegriP.Clonidine-mepivacaine mixture vs plain mepivacaine in pediatricsurgery. PaediatrAnaesth 1996;6:111-4.

[25]. Beauvoir C, Rochette A, Raux O, Ricard C, Canaud N, D'AthisF.Clonidine prolongation of caudal anesthesia in children.Anesthesiology 1994;81:A1347.

[26]. Jones RD, Gunawardene WM, Yeung CK. A comparison of lignocaine $2 \%$ with adrenaline 1;200,000 and lignocaine 2\% with adrenaline 1:200,000 plus fentanyl as agents for caudal anaesthesia in children undergoing circumcision. Anaesth Intensive

[27]. Care 1990;18:194-9.

[28]. Scott DA, Beilby DS, McClymont C. Postoperative analgesia usingepidural infusions of fentanyl with bupivacaine. A prospectiveanalysis of 1,014 patients. Anesthesiology 1995;83:727-37.

[29]. Penon C, Ecoffey C, Cohen SE. Ventilatory response to carbondioxide after epidural clonidine injection. AnesthAnalg 1991;72:761-4.

[30]. Motsch J, Böttiger BW, Bach A, Böhrer H, Skoberne T, Martin E.Caudal clonidine and bupivacaine for combined epiduraland general anaesthesia in children. ActaAnaesthesiolScand1997;41:877-83.

[31]. Mikawa K, Nishina K, Maekawa N, Asano M, Obara H. Oralclonidine premedication reduces vomiting in children afterstrabismus surgery. Can J Anaesth 1995;42:977-81.

[32]. Saumpelmann R, Busing H, Schroder D, Rekersbrink M, KrohnS,Strauss JM. Patient-controlled analgesia with clonidine andnpiritramide. Anaesthesist 1996;45:88-94. 